\title{
Desafios à inclusão dos alunos com deficiência auditiva numa aula de matemática
}

DOI 10.26512/lc.v25i0.23252

\author{
Anabela Cruz-Santos ${ }^{1}$ \\ CIEd, Universidade do Minho/PT \\ Maria Helena Martinho \\ CIEd, Universidade do Minho/PT
}

\section{Resumo}

Este artigo procura responder ao desafio de pensar a inclusão de alunos com Deficiência Auditiva em uma aula de Matemática. Nesse sentido, contrariamos o olhar simplista de ver o trabalho dos diferentes profissionais envolvidos sem que seja estabelecida uma coordenação entre eles. Ademais, propomos um conjunto de práticas de ensino para ajudar os professores de Matemática e o intérprete a enfrentarem as dificuldades inerentes à inclusão de alunos com Deficiência Auditiva na aula de Matemática e, em particular, desafiamos o desenvolvimento do trabalho colaborativo entre a equipe profissional envolvida.

Palavras-chave: Inclusão. Deficiência Auditiva. Matemática. Sala de aula. Equipe Multidisciplinar.

1 Doutora em Estudos da Criança (Educação Especial) pela Universidade do Minho, Portugal. É Professora da Universidade do Minho - Portugal, atuando no Departamento de Psicologia da Educação e Educação Especial (DPEEE).anabelacruz@gmail.com.

2 Doutora em Didáctica da Matemática pela Universidade de Lisboa, Portugal. É Professora da Universidade do Minho - Portugal, atuando no Instituto de Educação, no Departamento de Estudos Integrados de Literacia, Didáctica e Supervisão.mhm@ie.uminho.pt. 


\section{Resumen}

Este artículo busca responder al desafío de pensar la inclusión de alumnos con Deficiencia Auditiva en una clase de Matemáticas. Contrariamos la mirada simplista de ver a los diferentes profesionales involucrados con las respectivas funciones sin que se establezca una coordinación entre ellos. Proponemos un conjunto de buenas prácticas que ayudan a profesores de Matemáticas y al intérprete a enfrentar las dificultades inherentes a la inclusión de alumnos con Deficiencia auditiva en la clase de Matemáticas y, en particular, desafiamos al desarrollo de trabajo colaborativo entre los diferentes profesionales involucrados.

Palabras clave: Inclusión. Deficiencia Auditiva. Matemáticas. Sala de clase. Equipo multidisciplinario.

\section{Abstract}

This paper addresses the challenge of thinking about the inclusion of students with hearing impairment in a Mathematics class. We challenge the simplistic view which regards the different professionals involved in their functions without establishing a coordination between them. We propose a set of good teaching practices that help teachers of Mathematics and the interpreter to face the difficulties inherent to the inclusion of students with hearing impairment in the Mathematics class and, in particular, we discuss the development of collaborative work among the different professionals involved.

Keywords: Inclusion. Hearing Impairment. Mathematics. Classroom. Multidisciplinary Team. 


\section{Résumé}

Cet article tente de répondre au défi de penser à l'inclusion d'élèves ayant une déficience auditive dans un cours de mathématiques. Nous nous opposerions à la vision simpliste de voir les différents professionnels impliqués dans leurs fonctions sans établir de coordination entre eux. Nous proposons un ensemble de bonnes pratiques aidant les professeurs de mathématiques et l'interprète à faire face aux difficultés inhérentes à l'inclusion d'élèves ayant une déficience auditive en classe de mathématiques et, en particulier, nous mettons au défi le développement du travail collaboratif entre les différents professionnels impliqués.

Mots-clés: Inclusion. Déficience auditive. Mathématiques. Salle de classe. Equipe multidisciplinaire.

\section{Introdução}

Desde 2008, através da publicação do Decreto-Lei n. 3 , com a criação de escolas de referência da rede escolar pública e a implementação do bilinguismo que estão criadas as condições para garantir, aos alunos com deficiência auditiva, uma aprendizagem de todo o tipo de conteúdos curriculares, assim como usufruir de um extenso conjunto de conhecimentos (Carmo, Martins, Morgado, \& Estanqueiro, 2007). A inclusão é um princípio que prevê a inserção dos alunos com NEE nas escolas regulares, tanto em termos físicos, como sociais e acadêmicos, entendendo que a heterogeneidade que existe entre os alunos é um fator vantajoso, permitindo o desenvolvimento de comunidades escolares mais ricas (Correia, 2017). A inclusão de crianças e jovens com deficiência auditiva no espaço escolar deve proporcionar a criação de condições linguísticas e educacionais apropriadas para o desenvolvimento bilingue, a difusão desta língua além-fronteiras da escola, o entendimento de ser surdo, individual e coletivamente, dentro de uma lógica de cidadania. Tudo isto deve possibilitar a promoção da pluralidade, da tolerância, e da qualidade educativa (Coelho, 2005).

A legislação atual, o Decreto-Lei n. ${ }^{\circ}$ 4/2018, de 6 de julho continua a sustentar este princípio. Nesta peça legislativa fica patente o compromisso com a educação inclusiva, de acordo com a definição da UNESCO (2009), enquanto processo que visa responder à diversidade de necessidades dos alunos, através do aumento da participação de todos na aprendizagem e na vida da comunidade escolar. Nesse Decreto-Lei são referidos os recursos específicos de apoio à aprendizagem e à inclusão. Nomeadamente, no que diz respeito à educação dos alunos com problemas auditivos, é dada continuidade à 
existência das escolas de referência para a educação bilingue (art. 11) como recursos organizacionais específicos de apoio à aprendizagem e à inclusão. Em cada escola, o decreto prevê a constituição de uma equipe multidisciplinar de apoio à educação inclusiva, sendo composta por elementos permanentes e por elementos variáveis. São elementos permanentes da equipe multidisciplinar: a) um dos docentes que auxilia o diretor; b) um docente de educação especial; c) três membros do conselho pedagógico com funções de coordenação pedagógica de diferentes níveis de educação e ensino; d) um psicólogo. Compete às escolas a organização de respostas educativas diferenciadas, de acordo com os níveis de educação e de ensino e das características dos alunos, principalmente, através do acesso ao currículo, à participação nas atividades da escola e ao desenvolvimento de ambientes bilingues, promovendo a inclusão.

Essas escolas constituem uma resposta educativa especializada que permite assegurar ,acima de tudo, o desenvolvimento da Língua Gestual Portuguesa como a primeira língua dos alunos surdos, pois é aquela que os alunos adquirem com maior facilidade por ser uma língua natural e de modalidade visuo-gestual (Baptista, 2012).Vemos que é através da Língua Gestual que alunos se comunicam e têm acesso ao conhecimento, sendo a língua portuguesa a segunda língua deles.

Quando refletimos sobre a Língua Gestual Portuguesa e a língua portuguesa oral e escrita, surgem-nos ,logo, as dificuldades apresentadas por estes alunos, que muitas vezes condicionam o acesso a determinados níveis de leitura e por consequência o acesso à informação (Baptista, 2012). Apesar de se focar a atenção nas questões da linguagem, surge, também, a Matemática como uma área na qual o defasamento entre o nível alcançado pelos alunos com deficiência auditiva e os seus pares é uma realidade, conforme assinalado por diversos estudos (Tinoco, Martinho, \& Cruz-Santos, 2012). Desse modo, compreendemos que o domínio da Língua Gestual Portuguesa é crucial para o desenvolvimento individual, na sua construção como pessoa e no acesso ao conhecimento (Carmo et al., 2007).

Assim, procurando perceber a problemática da inclusão de alunos com deficiência auditiva nas aulas de Matemática, elencamos, neste texto, algumas dificuldades vividas pelos vários intervenientes nesse processo, as funções de cada um e um conjunto de boas práticas para o ensino da Matemática a alunos com deficiência auditiva (DA).

\section{Dificuldades enfrentadas na inclusão de alunos com DA}

Uma das grandes limitações ocasionadas por problemas auditivos é o acesso à linguagem escrita, mais propriamente ao alcance de níveis de leitura mais elevados (Baptista, 2012). As dificuldades na compreensão do duplo sentido de algumas palavras, o desconhecimento de alguns termos e o vocabulário reduzido, constituem 
importantes limitações no processo da leitura (Tinoco, Martinho, \& Cruz-Santos, 2018). Esses problemas são motivos de preocupação na comunidade educativa, pois a leitura é uma grande via de acesso à informação e faz a ponte para o conhecimento (Baptista, 2012). Desse modo, as escolas de referência para a educação e ensino bilingue constituem uma resposta educativa especializada com o objetivo de implementar o modelo de educação bilingue, enquanto garantem o acesso ao currículo nacional comum, assegurando, nomeadamente: a) o desenvolvimento da Língua Gestual Portuguesa (LGP) como primeira língua (L1); b) o desenvolvimento da língua portuguesa escrita como segunda língua (L2);c) a criação de espaços de reflexão e formação, incluindo a área da LGP, numa perspetiva de trabalho colaborativo entre os diferentes profissionais, as famílias e a comunidade educativa em geral. Assim, às escolas de referência, com a responsabilidade educativa e social de uma educação bilingue, cabe investir de forma a criar as condições necessárias para o acesso ao currículo, adequando os ambientes e espaços educativos à especificidade das crianças e dos jovens com deficiência auditiva (Pereira, 2009).

No caso de alunos com problemas auditivos, a comunicação ficará comprometida se for feita apenas através da língua oral, dificultando,dessa forma, o acesso ao conhecimento. Segundo Nunes, Evans, Barros,Burman (2014) e Vargas (2011), as crianças com deficiência auditiva apresentam desvantagem inicial em Matemática em relação aos seus pares ouvintes, acarretando,na maioria dos casos, um baixo desempenho nessa área. Nesse direcionamento, esse prejuízo pode ser ocasionado pelo fato de que ,na infância, as crianças com deficiência auditiva não construirem fundamentos matemáticos essenciais para obterem sucesso na Matemática formal da vida escolar (Nunes, 2010). Desse modo, o permanente envolvimento auditivo de uma criança ouvinte possibilita o acesso a aprendizagens incidentais, desempenhando um papel importante nos conhecimentos matemáticos informais. Em contrapartida, uma criança com deficiência auditiva, não tendo acesso a esse envolvimento, ficará limitada à exposição de oportunidades de aprendizagem de Matemática (Nunes, 2010).

Para que seja possível a comunicação entre o professor e o aluno com deficiência auditiva é indispensável que o docente domine a LGP ou possa contar com a presença de um intérprete de Língua Gestual na sala de aula. Segundo Spenassato e Giareta (2009), os professores, perante alunos com deficiência auditiva, sentem-se mais seguros com a presença de um intérprete nas suas aulas porque possibilita a comunicação. Além disso, os professores revelam preocupação sobre a aprendizagem dos educandos e sentem-se inseguros pelo fato de se julgarem mal preparados para desenvolverem métodos e adaptações necessárias a esses alunos (Sales, 2013).

Segundo Umbezeira (2013), "o conhecimento prévio em relação à Matemática pela criança surda ao chegar à escola costuma ser bem inferior ao de uma criança ouvinte da mesma idade" (p. 167). As crianças com deficiência auditiva apresentam uma experiência relativamente mais restrita, e isso reflete-se numa linguagem situada 
num nível mais concreto e conceptualmente mais limitado, pois não dispõem de tantas fontes de informação e de interações sociais como as crianças ouvintes (Nunes, 1998).

Alguns professores de alunos com deficiência auditiva consideram a Matemática uma disciplina de menor dificuldade em relação às outras, excetuando quando o trabalho recai na resolução de problemas, sendo necessária a interpretação dos enunciados (Arroio, 2013). É curioso observar que a situação se repete quando se questionam ,sobre o mesmo assunto, alunos com deficiência auditiva (Umbezeiro et al., 2013). Na realidade a Matemática possui uma linguagem própria, na qual a visualização adquire um aspeto importante sobre possíveis representações concretas que podem ocasionar a descoberta de relações abstratas (Sales, 2013). Desse modo, uma pessoa com deficiência auditiva compreende e interage com o mundo por meio de experiências visuais, sendo fundamental considerá-las no ensino de alunos com DA (Umbezeiro, Nogueira, Andrade, Borges, Silva, Zanquetta, Carneiro, \& Frizzarini, 2013).

No entanto, a linguagem matemática é constituída por termos muito específicos para os quais, na maior parte dos casos, não há tradução em língua gestual (Almendra, 2015; Umbezeiro et al., 2013). Portanto, o fato de o intérprete de língua gestual dar a possibilidade, ao aluno com deficiência auditiva, de ter acesso à informação através da sua língua natural já é muito bom, mas não é o suficiente para garantir a aprendizagem (Arroio, 2013). Assim, caso haja falta de gestos específicos para os termos utilizados na Matemática, o intérprete poderá recorrer à dactilologia ou ao alfabeto manual que permite a soletração das palavras por meio dos dedos das mãos que fazem gestos no espaço (Mesquita \& Silva, 2009) bem como à combinação de gestos ou utilização de códigos previamente definidos pelo intérprete e pelos alunos (Arroio, 2013). Somando-se a isso, temos o fato de que os intérpretes desconhecem ou não entendem os assuntos tratados, porque ,na maior parte dos casos, não possuem formação especializada sobre o que está sendo traduzido, podendo passar ideias erradas (Umbezeiro et al., 2013).

Nesse direcionamento, evidencia-se uma grande lacuna de investigação, em Portugal, na área da educação da Matemática com alunos com deficiência auditiva. Segundo Albino (2009), os estudos realizados em Portugal e relativos à educação de crianças com deficiência auditiva referem-se, sobretudo, aos primeiros anos de escolaridade e debruçam-se, majoritariamente, sobre a aprendizagem da escrita da língua portuguesa ou questões ligadas ao bilinguismo ou sobre as contribuições das relações familiares para o sucesso escolar dos Surdos. Por outro lado, no Brasil, a investigação envolvendo a deficiência auditiva e a Matemática é feita há décadas (Umbezeiro et al., 2013), sendo que as grandes conclusões assentam-se em três pilares: 1- a ampliação do vocabulário, em Língua Gestual, no campo da Matemática; 2- o conhecimento matemático; 3- metodologia apropriada (Arroio, 2013). Nota-se que é indispensável a continuidade de estudos que possam contribuir para a construção de uma base de gestos especificamente para o ensino da Matemática, a fim de proporcionar o acesso 
ao conhecimento (Sales, 2013). Visto que, a criança com deficiência auditiva, muito mais do que uma criança ouvinte, precisa de um "método ativo" de educação para contrabalançar com a inexistência de um canal tão importante de contato com o mundo (Umbezeiro et al., 2013). Pois, não basta traduzir para a língua gestual, conteúdos e estratégias metodológicas pensadas para o ensino da Matemática para crianças ouvintes, é necessária uma ação pedagógica que atenda as particularidades das crianças com deficiência auditiva (Sales, 2013), para alcançar um ensino de matemática de boa qualidade, que favoreça a inclusão do aluno na sociedade (Umbezeiro et al., 2013).

\section{Diferentes profissionais e suas funções}

As escolas dereferência paraa educação bilingue integram docentescomformação especializada em educação especial na área da surdez, docentes de LGP, intérpretes de LGP e terapeutas da fala que em colaboração com os demais professores do ensino regular constituem a equipe multidisciplinar, garantindo o acesso à informação e ao currículo, designadamente através de equipamentos e materiais de suporte visual às aprendizagens. Embora todos esses profissionais contribuam para a educação dos alunos com deficiência auditiva, focaremos nas funções dos profissionais que têm uma atuação mais direta na sala de aula de Matemática.

\section{O professor de Matemática}

O professor procura garantir que todos os alunos, numa mesma sala de aula, aprendam efetivamente matemática. Considerando a heteregenoidade dos mesmos, trata-se de uma tarefa permanentemente desafiante. Com base nos princípios orientadores para a ação do National Council of Teachers of Mathematics (NCTM, 2017) é possível elencar um conjunto de práticas de ensino que ajude a assegurar a todos o sucesso na aprendizagem da Matemática, entre as quais: estabelecer metas matemáticas para enfatizar a aprendizagem, propor tarefas que promovam o raciocínio e a resolução de problemas, usar e relacionar representações matemáticas, favorecer um discurso matemático significativo, colocar questões pertinentes e desafiantes, procurar a compreensão conceptual e não apenas a mecanização de processos, apoiar um esforço consequente na aprendizagem da Matemática, obter e utilizar evidência do pensamento matemático dos alunos. Todas essas práticas requerem um envolvimento ativo da parte do professor e do aluno.

Evidencia-se que concretização dessas práticas de ensino não é compatível com a 
clássica estrutura de aulas de ensino direto em que o professor "expõe" a matéria, apresenta exemplos e exercícios e o aluno resolve de acordo com os exemplos apresentados. Pelo contrário, através de um ensino exploratório, o aluno não se remete ao papel de "ouvir" e "repetir", mas tem um papel ativo e de diálogo (Guerreiro, Ferreira, Menezes, \& Martinho, 2015). Segundo Canavarro (2011) e Menezes, Oliveira e Canavarro (2015) o ensino exploratório da Matemática apesar de poder tomar formas diversas, tem um conjunto de elementos que o caracterizam: o professor seleciona tarefas desafiantes e adequadas aos alunos para que a aprendizagem seja significativa (Stein \& Smith, 1998); o professor presta atenção aos alunos, áquilo que dizem, escrevem e constroem, baseando nessa atenção a sua atuação na aula e a planificação das aulas seguintes; o professor organiza a aula em quatro fases apresentação da tarefa, realização da tarefa pelos alunos, discussão da tarefa na qual se confrontam as diferentes abordagens dos alunos e, por fim, a sistematização das aprendizagens matemáticas. A realização das tarefas em grupos heterogêneos, "responsabilizando" os alunos pela aprendizagem dos seus colegas, transporta um forte potencial para o desenvolvimento de capacidades matemática e sociais (Boaler, 2016). O ensino exploratório revela-se, pois, como um meio privilegiado para criar um ambiente de aprendizagem produtivo e com significado para os alunos.

No entanto, essas diferentes práticas de ensino só são possíveis quando está presente um conjunto de cinco elementos essenciais: garantia de acesso e equidade, currículo poderoso e desafiante, materiais adequados, avaliação congruente e significativa, e, ainda, profissionalismo (NCTM, 2017). Assim, garantir o acesso e a equidade, não significa que todos os alunos aprendam o mesmo e da mesma forma. Pelo contrário, o estudante deve ser percebido de acordo com as suas necessidades. Nesse contexto, um educando com deficiência auditiva, para otimizar o rendimento de uma aula, deve ter acesso a materiais manipuláveis e tecnológicos convenientes, materiais previamente escritos com todos os registros da aula bem como a presença de um intérprete de LGP. Pois, não raro, as capacidades dos alunos são subestimadas, restringindo a oportunidade deles terem acesso a atividades desafiantes. Assim, perante a diversidade de materiais existentes, tais como: os escritos, os tecnológicos e os manipuláveis, é essencial que o professor recorra a todas as possibilidades para potenciar a aprendizagem de cada um dos seus alunos.

Desse modo, espera-se que a avaliação seja vista como um processo contínuo, coerente e significativo, integrado ao ensino e à aprendizagem. Ou seja, uma forma de ajudar o aluno a compreender e valorizar o seu progresso. Para isso, determinadas ações do professor são essenciais, como por exemplo: explicar, questionar, ouvir e responder (Menezes, Ferreira, Martinho, \& Guerreiro, 2014). No entanto, a interação com os alunos com deficiência auditiva estará comprometida se o professor não tiver conhecimento de LGP, ou dependente, no caso de contar com a presença de um intérprete de Língua Gestual na sala de aula. 
Adicionando-se ao que foi dito, Anthony e Walshaw (2009) apontam quatro dimensões do papel do professor: construção de uma comunidade matemática, garantia do discurso na sala de aula, cuidado com as tarefas e sustentação do conhecimento. Portanto, a preocupação com a construção de uma comunidade pressupõe que o professor envolva todos os alunos, mesmo que assumindo diferentes papéis, de modo que cada um se sinta membro efetivo dessa comunidade. Em se tratando do discurso na sala de aula, o uso de diversas representações é essencial, tais como: orais, escritas e com recursos a diferentes materiais. Desse modo, o professor procura progressivamente garantir o uso de uma linguagem matemática mais elaborada, levando o aluno a apoderar-se dela de forma natural. Para tanto, a escolha das tarefas é um aspecto essencial (Stein \& Smith, 1998), e o professor deve garantir que elas contribuam para a evolução matemática dos seus alunos ao nível do próprio pensamento matemático. Ademais, as tarefas devem ser poderosas permitindo o confronto de ideias e processos de resolução, o estabelecimento de conexões entre temas da Matemática e entre representações ,dando sentido à mesma. Nesse sentido, a sustentação do conhecimento envolve diferentes vertentes: o conhecimento matemático sólido, o conhecimento pedagógico do conteúdo e da forma como os alunos aprendem e, ainda, o conhecimento do aluno, mais precisamente de cada aluno em particular (Martinho \& Gil, 2014; Rowland, 2008). Nota-se, pois, que esse conhecimento permite que o professor selecione e explore as tarefas, que tenha a percepção do que é essencial e acessório na Matemática, que ajude os alunos a ultrapassar dúvidas.

\section{O interprete de LGP}

O intérprete de Língua Gestual Portuguesa faz parte de grupo profissional recente e, consequentemente, ainda pouco expressivo em termos numéricos. Por esse motivo, deparam-se com inúmeros desafios ao longo do seu percurso profissional. Perante essa questão, é urgente clarificar as suas funções junto dos alunos com surdez e ouvintes para perceber a extensão e os limites da atuação desses profissionais (Barbosa, Martins, Macedo, \& Sousa, 2016).

Nesse sentido, o reconhecimento das línguas gestuais como línguas naturais das comunidades surdas, associado a uma participação das pessoas na sociedade, veio tornar cada vez mais requisitada a presença de intérpretes de língua gestual, para que as barreiras de comunicação fossem derrubadas. Deste modo, pouco a pouco, foram surgindo cursos de formação, organizados pelas associações de surdos, o que criou condições para a implementação da profissão de intérprete de língua gestual (Cordova, 2009; Rodríguez, 2004 citados por Barbosa, Martins, Macedo, \& Sousa, 2016).

Assim, o intérprete de língua gestual é o profissional que domina a língua de sinais e 
a língua falada no país e que é qualificado para desempenhar a função de intérprete. Em Portugal, essas línguas são a LGP e a língua portuguesa. Um intérprete de Línguas Gestuais transmite informações faladas e escritas para que todos os indivíduos possam comunicar entre si (Barbosa, Magalhães, Silva, Silva, Santos, Freitas, Ramos, \& Costa, 2016). O trabalho do intérprete consiste em interpretar tudo o que o professor oraliza, incluindo quaisquer atos dirigidos a outros alunos da turma, ou ao intérprete. Não existe consenso sobre o que deve ser efetivamente a função do intérprete de língua gestual, ou seja, quais os seus limites de atuação e o seu enquadramento profissional nos mais variados domínios, especificamente no caso do intérprete educativo que atua em contextos escolares. É ainda uma profissão que carece de linhas orientadoras legais e, por isso, cabe a cada intérprete a responsabilidade de decidir individualmente as características do seu trabalho (Barbosa, Martins, Macedo, \& Sousa, 2016).

\section{O professor de Educação Especial}

O docente de educação especial, no âmbito da sua especialidade, apoia, de modo colaborativo e numa lógica de corresponsabilização, os demais docentes do aluno na definição de estratégias de diferenciação pedagógica, no reforço das aprendizagens e na identificação de múltiplos meios de motivação, representação e expressão. Correia (2008) defende que os Professores de Educação Especial devem assumir as suas competências profissionais atuando como consultores de apoio junto dos professores do ensino regular, sendo responsáveis por ajudá-los no desenvolvimento de estratégias e atividades que apoiem a inclusão dos alunos com NEE nas turmas regulares. Além disso, Correia $(2008 ; 2017)$ designa como competências concretas do Professor de Educação Especial, tanto a nível da sua participação em Equipes Multidisciplinares, como em trabalho a realizar junto de alunos, professores e outros profissionais, as seguintes: a) modificar (adequar) o currículo comum para facilitar a aprendizagem da criança com NEE; b) propor ajuda suplementar e serviços de que o aluno necessite para ter sucesso na sala de aula e fora dela; c) alterar as avaliações para que o aluno possa vir a mostrar o que aprendeu; d) estar ciente de outros aspectos do ensino, designadamente do ensino individualizado, que possam responder às necessidades do aluno; e) colaborar com os professores (ensino em cooperação); f) efetuar trabalho de consultoria (a professores, pais, outros profissionais de educação); g) efetuar planificações em conjunto com professores de turma; h) trabalhar diretamente com o aluno com NEE (na sala de aula ou sala de apoio a tempo parcial, se determinado no Programa Educativo Individual -PEI do aluno).

À medida que a inclusão se tornou o modelo predominante para a educação de alunos surdos, mais estudantes frequentam a escola pública do bairro ou aquela 
perto da sua residência, onde recebem serviços de apoio da equipe multidisciplinar. Esses profissionais deverão trabalhar com os alunos nas atividades acadêmicas, na comunicação, além de fornecer apoio e consultoria aos profissionais da escola e aos pais. Os serviços de apoio especializado baseiam-se nas necessidades do aluno e são geralmente documentados no Programa Educativo Individual (PEI) do aluno. Destaca-se que uma das tarefas do professor de EE é apoiar o progresso acadêmico dos alunos, dentro e fora da sala de aula. O apoio dentro da sala de aula pretende auxiliar os alunos na realização dos trabalhos em grupo ou em sala de aula, ou, ainda, em ambientes informais, como atividades no recreio ou na hora do almoço, a fim de abordar o desenvolvimento das competências sociais e de comunicação (Correia, 2017).

\section{Práticas para o ensino da matemática com alunos com deficiência auditiva}

As práticas aqui apresentadas são consideradas especialmente adequadas para ensinar Matemática a alunos com deficiência auditiva. Algumas foram pensadas especificamente para eles, enquanto outras são apropriadas para aulas que incluem alunos surdos e seus pares. Existe uma variedade de materiais impressos e on-line, muitos dos quais dão aos alunos acesso à Matemática por meio de atividades que envolvem leitura, escrita, uso de gestos e outros meios de comunicação. A intenção dessas propostas relativas à área de Matemática é fornecer aos professores estratégias que enfatizem a resolução de problemas e o envolvimento dos alunos na aprendizagem da Matemática.

Algumas propostas tem por base preparar previamente algum complemento ao material disponibilizado para a aula. Por exemplo, é muito difícil para um aluno com deficiência auditiva tomar notas durante uma aula. Repare-se que o aluno precisa de estar atento ao professor, ao intérprete e aos materiais (Tinoco, Martinho, \& CruzSantos, 2018). O professor enquanto fala, gesticula, aponta e faz expressões que, mesmo não ouvindo, podem ser relevantes e, naturalmente, despertam a atenção do aluno. O intérprete traduz o que é dito para a língua gestual. O professor recorre ao quadro enquanto fala ou a algum material tecnológico ou manipulável e o aluno precisa prestar atenção também a isso. Claro que se o aluno tentar escrever no caderno, o processo ainda se complica mais. Um aluno regular pode escrever sem deixar de perceber o que se passa na aula, porém, um aluno com deficiência auditiva perde naturalmente informação quando se desliga desse campo visual.

Para atenuar essas dificuldades, e com base nos princípios orientadores para a ação do National Technical Institute for the Deaf (RIT, 2017) as seguintes estratégias podem ser implementadas: a) fornecer cópias de folhetos e apresentações utilizadas na 
aula e acesso da forma escrita a outra informação relevante; b) escrever conceitos importantes, e vocabulário relevante no quadro e dar tempo para que esse seja passado para o caderno ou fotografado pelo aluno; c) fornecer desenhos, esquemas ou tabelas que sejam apresentadas na aula para que o aluno abrevie o tempo necessário para a escrita; d) fornecer a transcrição de vídeos relativos a conteúdos programáticos que sejam visionados na aula, onde o aluno poderá fazer anotações; e) recolher com regularidade o caderno do aluno para monitorizar a aprendizagem, e complementar informação.

Evidencia-se que quando o professor de Matemática não sabe ou não é fluente em língua gestual precisa de um intérprete na sala de aula. Assim, nas escolas de referência, o mesmo intérprete acompanha a turma nas aulas de diferentes disciplinas e o conhecimento sobre o conteúdo lecionado pode ser reduzido. Além disso, muitos conceitos matemáticos podem não ter tradução para a Língua Gestual Portuguesa. Para minimizar esses problemas, o professor pode fornecer ao intérprete uma planificação da aula em que conste a listagem de termos matemáticos essenciais e as respectivas definições para que ele possa procurar os gestos ou, no caso de ser necessário, os consiga explicar de forma cuidadosa, sem criar confusão desnecessária aos alunos. Recorde-se, a título de exemplo, um episódio relatado em Tinoco, Martinho e Cruz-Santos (2018) em que a insuficiência de gestos em LGP para designar os objetos matemáticos razão e fração originou conversas descoordenadas entre a professora e uma aluna. A intérprete utilizava a mesma sequência de gestos para os dois conceitos: gesto do número do numerador - gesto de traço de fração - gesto do número do denominador. Por outro lado, a professora se esforçava para que a aluna compreendesse a diferença entre os dois conceitos, porém ela não conseguia compreender onde é que a professora queria chegar.

Entende-se, pois, que no processo de ensino-aprendizagem é importante que o professor potencie todos os recursos disponibilizados pelas escolas de referência. Propomos, a seguir, uma síntese com algumas propostas que podem ser implementadas pelo professor e pelo intérprete visando à potencialização da aprendizagem do aluno. 
Quadro 1.Práticas para o Ensino da Matemática para alunos com DA

Antes da aula

Elabora o plano assinalando (para o interprete):

- os termos matemáticos essenciais;

- a(s) tarefa(s);

- listagem dos materiais a utilizar;

- os momentos da aula;

- as formas de trabalho (individual, pequeno grupo, grupo turma).

Elabora um documento (para o aluno) com:

- uma síntese dos aspetos essenciais da aula;

- o enunciado da(s) tarefa(s) acompanhado de imagens de objetos ou contextos.

\section{Elabora em colaboração com o Professor de}

Educação Especial o Programa Educativo Individual, tendo em conta as necessárias adaptações curriculares para o aluno.

\section{Estuda o plano de aula:}

- os sinais de LG e a sua correspondência com o Português e vice-versa;

- as tarefas e materiais que vão ser utilizados na aula para que os explique claramente;

- assinala os diferentes momentos para saber como se deve posicionar na sala e em relação ao aluno.

Apoia na realização das acomodações curriculares e seleção e implementação das medidas a aplicar ao aluno (Tecnologias de Apoio, adaptação de materiais e recursos educativos, combinação adequada de vários métodos e estratégias de ensino, etc)

Elabora o Programa Educativo Individual (PEI) em colaboração com o Professor de Matemática e outros técnicos especializados que fazem parte da Equipa Multidisciplinar (Terapeutas da Fala, Psicólogo, etc).
Na aula

Fala sempre voltado para o aluno com deficiência auditiva.

Respeita o fato de o intérprete precisar de tempo para: esclarecer/comentar o que o aluno disse; introduzir explicações de situações que ocorrem na aula que não foram planificadas.

Respeita o fato do intérprete precisar de fazer uma pausa por hora para descansar.

Esclarece de forma clara as normas de segurança e de utilização de equipamentos e materiais utilizados nas aulas.

Traduz para LG tudo o que o professor ou colegas dizem na aula relacionadas com os conteúdos:

- questões, respostas e comentários dos pares e do professor que são ditas em grupo turma;

- falas dirigidas dos pares para o aluno com DA;

- falas do professor para o aluno com DA;

Traduz para Língua Portuguesa tudo o que o aluno com DA diz:

- para o professor;

- para os pares;

- para a turma.

Trabalha com o aluno de acordo com o programa estabelecido ou quando solicitado para isso.

Fonte: (National Technical Institute for the Deaf, 2017; DL. 54/2018) 


\section{Considerações Finais}

Este artigo centrou-se na inclusão de alunos com Deficiência Auditiva na sala de aula de Matemática. Apesar de termos plena consciência de muitos outros problemas inerentes à prática profissional de um professor de Matemática, procurou-se identificar algumas dificuldades levantadas quando da intervenção junto desses alunos. Este artigo focou-se numa identificação de práticas de suporte para a aprendizagem e inclusão, em função das características de cada aluno relativas ao ensino de Matemática com alunos com deficiência auditiva. Procuramos elencar um conjunto de práticas recomendadas a nível internacional e nacional, que podem ajudar o professor a ultrapassar as dificuldades enfrentadas com a inclusão de alunos com deficiência auditiva nas suas aulas. O conhecimento de uma diversidade de estratégias permite que inúmeras dificuldades sejam ultrapassadas, de modo a assegurar que cada aluno tenha acesso ao currículo e às aprendizagens, levando todos a explorar as suas potencialidades ao máximo.

\section{Agradecimentos}

Este trabalho é financiado pelo CIEd - Centro de Investigação em Educação, projetos UID/CED/1661/2013 e UID/CED/1661/2016, Instituto de Educação, Universidade do Minho, através de fundos nacionais da FCT/MCTES-PT.

\section{Referências bibliográficas}

Almendra, I. M. S. (2015). Análise e identificação dos termos matemáticos utilizados no $1 .^{\circ}$ e $2 .^{\circ}$ ciclos do Ensino Básico e sua correspondência na Língua Gestual Portuguesa. Dissertação de Mestrado, Universidade do Minho, Portugal.

Albino, I. (2009). Alunos surdos e a matemática: Dois estudos de caso no $12 .^{\circ}$ ano de escolaridade do ensino regular. Dissertação de Mestrado não publicada, Faculdade de Ciências, Universidade de Lisboa, Portugal.

Amaral, M. A., Coutinho, A., \& Martins, M. R. (1994). Para uma gramática da Língua Gestual Portuguesa. Braga: Psiquilibrios. 
Anthony, G., \& Walshaw, M. (2009). Characteristics of effective teaching of Mathematics: A view from the West. Journal of Mathematics Education, 2(2), 147164.

Arroio, R. (2013). Ensino de Matemática para alunos surdos com a utilização de recursos visuais. Dissertação de Mestrado não publicada, Universidade Federal Rural do Rio de Janeiro, Brasil.

Baptista, M. (2012). Educar e comunicar na surdez. Coimbra: Grácio Editor.

Barbosa, S., Martins, T., Macedo, V., \& Sousa, A. L. (2016). O/a intérprete de Língua Gestual Portuguesa e o voluntariado. Educação, Sociedade \& Culturas, 191- 207.

Barbosa, S., Magalhães, A., Silva, J., Silva, L., Santos., M., Freitas., P., Ramos., V., \& Costa, V. (2016). O intérprete de Língua Gestual Portuguesa: Conhecer a profissão. Belas Infiéis, 5(1), 131-146.

Boaler, J. (2016). Mathematical mindsets: Unleashing students' potential through creative math, inspiring messages and innovative teaching. San Francisco: Jossey-Bass.

Canavarro, A. P. (2011). Ensino exploratório da Matemática: Práticas e desafios. Educação e Matemática, 115, 11-17.

Carmo, H., Martins, M., Morgado, M., \& Estanqueiro, P. (2007). Programa Curricular de Língua Gestual Portuguesa - Educação Pré-Escolar e Ensino Básico. Ministério da Educação - DGIDC.

Coelho, O. (2005). Perscrutar e escutar a surdez. Santa Maria da Feira: Afrontamento.

Correia, L. M. (2008). Inclusão e necessidades educativas especiais: Um guia para educadores e professores. Porto: Porto Editora.

Correia, L. M. (2017). Fundamentos em educação especial: Guia prático para educadores e professores. Braga: Flora Editora.

Guerreiro, A., Ferreira, R. A. T., Menezes, L., \& Martinho, M. H. (2015). Comunicação na sala de aula: a perspetiva do ensino exploratório da matemática. Zetetiké, 23(44), 279-295.

Martinho, M. H., \& Gil, P. D. B. (2014). O professor e o desenvolvimento da capacidade de argumentação: Equações do 2. grau na Antiga Babilónia com alunos do 9. ${ }^{\circ}$ ano. In J. P. da Ponte (Org.), Práticas profissionais de professores de Matemática (pp. 313-340). Lisboa: Universidade de Lisboa.

Menezes, L., Ferreira, R. A. T., Martinho, M. H., \& Guerreiro, A. (2014). Comunicação nas práticas letivas dos professores de Matemática. In J. P. da Ponte (Org.), Práticas 
profissionais de professores de Matemática (pp. 135-161). Lisboa: Universidade de Lisboa.

Menezes, L., Oliveira, H., \& Canavarro, A. P. (2015). Inquiry-based mathematics teaching: The case of Célia. In U. Gellert, J. Gimenez Rodriguez, C. Hahn \& S. Kafoussi (Eds.), Educational paths to Mathematics (pp. 305-321). Cham: Springer.

Mesquita, I., \& Silva, S. (2009). Guia prático de Língua Gestual Portuguesa - Ouvir o silêncio. Braga: Editora Nova educação, Lda.

Morgado, M. (2012). Ensinar e aprender a Língua Gestual Portuguesa como L2. Lisboa: Universidade Católica Editora.

National Council of Teachers of Mathematics (2017). Princípios para a ação: Assegurar a todos o sucesso em Matemática. Lisboa: Associação de Professores de Matemática.

National Technical Institute for the Deaf (2017). An Overview: The best education for deaf and hard-of-hearing students. Rochester: RIT.

Nunes, R. (2000). Perspectivas na integração da pessoa surda. Coimbra: Gráfica de Coimbra.

Nunes, T., \& Moreno, C. (1998). Promoting deaf pupils' achievement in mathematics. Acedido a Abril, 14, 2013 em http://www.acfos.org/publication/ourarticles/pdf/ acfos $3 /$ nunes.pdf.

Nunes, T., Barros, R., Evans, D., \& Burman, D. (2014). Improving deaf children's working memory through training. International Journal of Speech and Language Pathology and Audiology, 2, 51 - 66. doi: 10.12970/2311-1917.2014.02.02.1

Pereira, F. (2008). Educação Especial: Manual de apoio à prática. Lisboa: Ministério da Educação/DGIDC.

Pereira, F. (2009). Educação bilingue de alunos surdos: Manual de apoio à prática. Lisboa: Ministério da Educação/DGIDC.

Rowland, T. (2008). Researching teachers' mathematics disciplinary knowledge. In P. Sullivan \& T. Wood (Eds.), International handbook of mathematics teacher education: Knowledge and beliefs in mathematics teaching and teaching development (pp. 273298). Rotterdam: Sense.

Sales, E. R. (2013). A visualização no ensino de Matemática: Uma experiência com alunos surdos. Tese de Doutoramento não publicada, Universidade Estadual Paulista (Unesp), Instituto de Geociências e Ciências Exatas, Rio Claro, Brasil. 
Spenassato, D., \& Gianeta, M.(2009). Inclusão de alunos surdos no ensino regular: Investigação das propostas didático-metodológicas desenvolvidas por professores de matemática no Ensino médio da EENAV. X Encontro Gaúcho de Educação Matemática, Brasil.

Stein, M. K., \& Smith, M.S. (1998). Mathematical tasks as a framework for reflection. Mathematics Teaching in the Middle School, 3(4), 268-275.

Tinoco, J., Cruz-Santos, A., \& Martinho, M. H. (2013). Comunicação nas aulas de Matemática: Um estudo de caso numa turma do 6. ano. In L. S. Almeida, B. D. Silva, \& A. Franco (Orgs.), Proceedings of XII Congresso Internacional Galego-Português de Psicopegagogia (pp. 5402-5417). Braga: Universidade do Minho.

Tinoco, J., Martinho, M. H., \& Santos, A. C. (2018). O uso da língua gestual portuguesa na aprendizagem matemática em alunos com deficiência auditiva: Resultados preliminares. Revista de Educação Matemática - REMat, 15(20), 445-462.

Umbezeiro, M. B., Nogueira, C., Andrade, D., Borges, F., Silva, M., Zanquetta, M., Carneiro, M., \& Frizzarini, S. (2013). Surdez, inclusão e matemática. Curitiba- Brasil: Editora CRV.

UNESCO (2009). Policy guidelines on inclusion in education. France: United Nations Educational, Scientific and Cultural Organization.

Vargas, R. C. (2011). Composição aditiva e contagem em crianças surdas: Intervenção pedagógica com filhos de surdos e ouvintes. Tese de Doutoramento não publicada, Universidade Federal do rio Grande do Sul. Porto Alegre, RS, Brasil.

Legislação consultada

Decreto-Lei $n^{\circ} 3 / 2008$ de 7 de janeiro

Decreto-Lei n. $54 / 2018$ de 6 de julho

Resolução da Assembleia da República n. 56/2009

Decreto do Presidente da República n. $71 / 2009$ 